\title{
Challenging Experience with Severe Complicated Malaria in the City of Dhaka
}

\author{
Refaya Tasnim ${ }^{*}$, Quazi Tarikul Islam²
}

\begin{abstract}
Malaria is a vector-borne febrile illness that requires an association of three factors- parasite, vector, and host- to continue its life cycle. The physical and cultural environments, as rainfall, humidity, and temperature permitted Bangladesh to be a malaria-endemic area, where Plasmodium falciparum is the dominant parasite and accounts for $93 \%$ of the malaria cases in the country. Due to the high degree of severity of the disease and about 15\% of total annual deaths in Bangladesh, in the year of 1961, Malaria Eradication Program (MEP) was introduced. NMEP caused a significant reduction in total malaria incidences, severity and deaths. Still $33.6 \%$ of the total population in Bangladesh is at risk of malaria and the majority of cases are reported in 13 endemic areas of 64 districts in the country. Above all, resurgence of malaria and treatment resistant cases have become a burning issue to think about in recent years. Here, we present two severe falciparum malaria cases that challenged us with the complicated nature of the disease in Dhaka city, which is not listed as a malaria endemic zone of Bangladesh.
\end{abstract}

Keywords: Severe falciparum malaria, Resurgence of malaria, Dhaka city
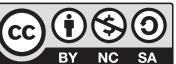

DOI: https://doi.org/I0.3329/jom.v23il.57943

Copyright: (C) 2022 .Tasnim R. This is an open access article published under the Creative Commons Attribution-NonCommercial-NoDerivatives 4.0 International License, which permits use, distribution and reproduction in any medium, provided the original work is properly cited, is not changed in any way and it is not used for commercial purposes.

Received: 23 December, 202I;

Accepted: 25 December, 2021

\section{Introduction}

Malaria is a complex illness due to its highly nonspecific clinical features. In Bangladesh, two malarial parasitesPlasmodium malariae, Plasmodium falciparum, and three vectors, A. philippinesis, A. sundaicus and A. minimus, are found during most of the year ${ }^{1}$. Clinical features of malaria have a wide range from fever with prominent chills and discomfort to cerebral malaria, multi organ dysfunction as acute liver failure, ARDS, AKI. Cerebral malaria is a common entity in children, while multi-organ failure mostly occurs in adults. The diagnosis depends on a high degree of clinical suspicion and confirmation by detecting the asexual form of malarial parasite and estimation of parasite density in peripheral blood smear by microscopy; which is gold standard due to its cost-effectiveness, sensitivity, and high degree of specificity. The frequency of manifestations of severe malaria varies with the intensity of transmission: In Africa, where the transmission of malaria is intense and stable, severe malaria is mainly a disease of children till the age of five years. In areas of low to moderate transmission (SouthEast Asia) people of all age groups are vulnerable to severe malaria.
In the last two decades, a paradigm shift has been noticed regarding the clinical manifestations of malaria. Multi-organ involvement like acute renal failure, respiratory distress is encountered much more frequently than before and this changing scenario could be ascribed to high transmission of falciparum malaria and drug-resistance to commonly used antimalarial agents. So, if parasitological confirmation is likely to be delayed, specific anti-malarial therapy should be started based on the clinical diagnosis, as it is considered to be life-saving.

In south-east Asia, Bangladesh is one of the four major malariaendemic countries having approximately $34 \%$ of its population at risk of malaria. Bangladesh now has a strong ground for its very well controlled National Malaria Elimination Program (NMEP). Still, 19 million people in 13 malaria-endemic districts endure the brunt of the disease, prevalence ranging between $3.1 \%$ and $36 \% \%^{2}$, who share boundaries with the eastern states of India and Myanmar. Among them, the Chattogram Hill Tracts (CHT) stands as the highest risk zone, contributing about $93 \%$ of malaria cases in the country and the highest of the CHT can be found in Bandarban district, contributing about $60 \%$ of the total number of confirmed cases in Bangladesh since 2017. [Figure 1]

1. Assistant Registrar of Medicine, Popular medical college \& hospital

2. Professor of Medicine, Popular medical college \& hospital

*Corresponding author: Dr. Refaya Tasnim- Assistant Registrar of Medicine, Popular medical college \& hospital 


\section{Malaria endemic areas in Bangladesh}

\begin{tabular}{llc}
\hline Name of district & $\begin{array}{c}\text { No of sub } \\
\text { District }\end{array}$ \\
\hline 1. Kurigram & 2 \\
2. Shherpur & 2 \\
3. Mymensingh & 2 \\
4. Netrokona & 2 \\
5. Sunamgonj & 6 \\
6. Sylhet & 4 \\
7. Moulvibazar & 6 \\
8. Hobigonj & 2 \\
9. hittagong & 13 \\
10. Khagrachari & 8 \\
11. Rangamati & 10 \\
12. Bandarban & 12 \\
13. Cox's Bazar & 13 \\
\hline
\end{tabular}

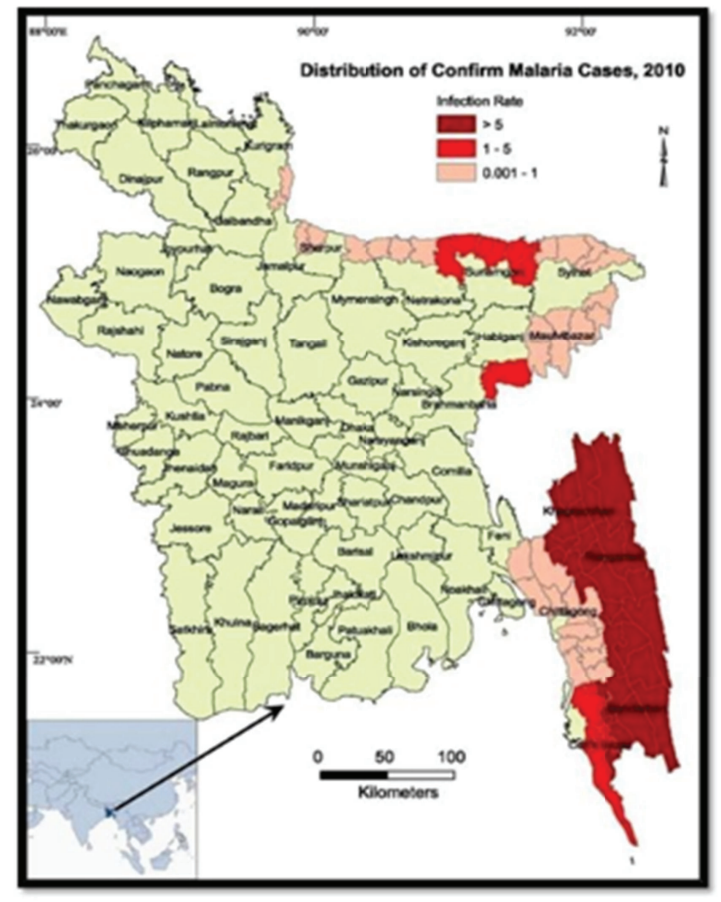

Fig.-1: Malaria endemic areas in Bangladesh

There is a resurgence of malaria in recent years, attributed to two major factors- the Forcibly Displaced Myanmar Nationals (FDMNs) from Myanmar to Bangladesh since $25^{\text {th }}$ august, 2017, and the global pandemic of COVID-19 pneumonia which was confirmed to have spread here in March, 2020. As a consequence, the anti-malarial movement has been curtailed up to the point that, now we have to deal with severe malaria cases even in the non-endemic zone of the country.

\section{Case summary}

A 38-years-old normotensive, non-diabetic young male, marine engineer by profession hailing from Narayanganj, Dhaka was admitted to a tertiary care hospital ICU via emergency on the night of early November, 2021, with the complaints of high-grade fever for 6days, headache $\&$ body ache for 3 days, and high coloured urine for 1day. His fever was continued in nature, highest recorded temperature was $104^{\circ} \mathrm{F}$, associated with severe chills and rigor, subsided by taking Paracetamol with profuse sweating. Fever was not associated with any rash. His headache was severe, generalized, band like, and not associated with photophobia or vomiting. There was no retro-orbital pain. No history of convulsion. He had generalized body ache, not associated with any joint pain or swelling. His urine was high coloured for 1day, urine volume was normal, not associated with burning sensation, urinary frequency or urgency. He also noticed progressive yellow discoloration of sclera for the same duration. He lost his appetite and was nauseous. His bowel habit was normal. Other than his laparoscopic cholecystectomy on July, 2021, he had no other significant past illness to mention.

On query, he stated that, he went on trekking for 7 days to Chattogram Hill Tracts area (Bandarban), 8-10days before his illness. He did not take any prophylaxis for malaria before travelling.

On admission, his pulse was 140bpm, blood pressure 120/80 $\mathrm{mmHg}$, Temperature $104^{\circ} \mathrm{F}$, respiratory rate 40 breaths/minute, $\mathrm{SpO} 296 \%$ with 2LO2/minute via nasal cannula, RBS $3.2 \mathrm{mmol} /$ L. On general examination, he was well oriented and conscious, average body built, moderately icteric [Figure2], moderately anemic, mild bipedal pitting edema was present. He had no rash or lymphadenopathy. Tornequate test was negative, and flapping tremor was absent.

On systemic examination, inspection of the oral cavity revealed smooth, raw-beef tongue, there were no oral ulcers or bleeding spots present, and lips, gum, teeth were healthy [Figure-3]. Abdomen was mildly distended with inverted umbilicus. There was mild tender hepatomegaly on palpation, but no other organomegaly was present. On percussion, shifting dullness was positive, but fluid thrill was absent. 


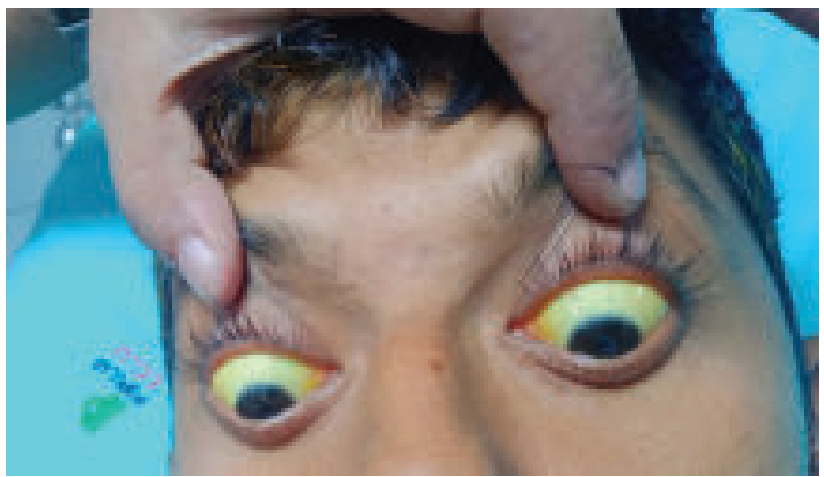

Fig.-2: Moderate jaundice seen

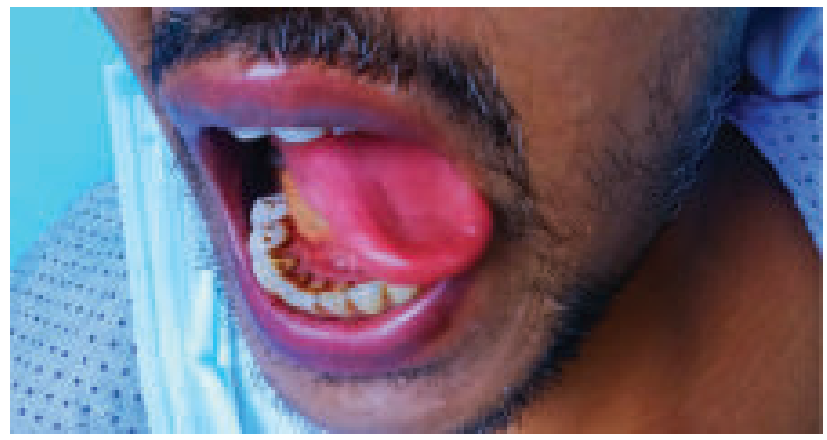

Fig.-3: smooth raw-beef like tongue in the upper sclera

Despite having high respiratory rate, auscultation of the chest revealed vesicular breath sound with no added sound, which pointed towards acidotic breath. Cardiovascular examination was normal and nervous system examination was normal, no sign of meningeal irritation was present, his ophthalmoscopic examination was also normal.

Patient had catheter in situ with very high coloured urine. [Figure-4]

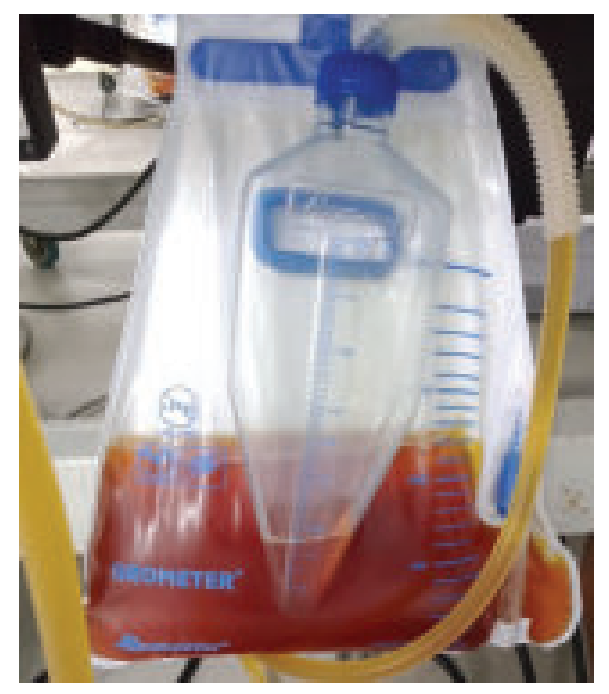

Fig.-4: Very high coloured urine on admission
After admission, his initial lab reports were as follows, Full blood count: Hemoglobin: 8.70 g/dL, HCT: $25.20 \%$, Total WBC count: $12.75 \mathrm{~K} / \mu \mathrm{L}$, Neutrophil: $80 \%$, Lymphocyte: $18 \%$, Platelet count: $20 \mathrm{~K} / \mu \mathrm{L}, \mathrm{ESR}: 02 \mathrm{~mm}$ in $1^{\text {st }}$ hour. S. creatinine: $3.20 \mathrm{mg} / \mathrm{dL}$, S. Urea: $140 \mathrm{mg} / \mathrm{dL}$, ABG showed metabolic acidosis: $\mathrm{pH} 7.2, \mathrm{pCO} 2: 25.1, \mathrm{pO} 2: 39.7, \mathrm{HCO} 3: 11.5 \mathrm{mmol} / \mathrm{L}$. Electrolytes report showed mild hyponatremia (Sodium: 126 $\mathrm{mmol} / \mathrm{L}$ ), and hypocalcemia (Calcium: $6.80 \mathrm{mg} / \mathrm{dL}$ ).

Urine R/E: pus cells 2-4/HPF, RBC: 4-6/HPF, Bilirubin: ++, Urobilinogen: +++

LFT was highly altered: Transaminases were high, SGPT: $148 \mathrm{U} / \mathrm{L}, \mathrm{SGOT}$ : $318 \mathrm{U} / \mathrm{L}$; hyperbilirubinemia, mostly unconjugated: Total bilirubin: $19.64 \mathrm{mg} / \mathrm{dL}$, direct: $11.56 \mathrm{mg} /$ $\mathrm{dL}$, indirect: $8.08 \mathrm{mg} / \mathrm{dL}$; S. albumin: $2.33 \mathrm{~g} / \mathrm{dL}$; PT: 17 seconds (INR 1.46); APTT: 50 seconds. S. lipase: 2267 U/L. S. amylase and S. ammonia were within normal range.

Inflammatory markers were as follows: CRP: $269 \mathrm{mg} / \mathrm{L}, \mathrm{S}$. ferritin: $36583.53 \mathrm{ng} / \mathrm{mL}$, D-dimer: $22.35 \mu \mathrm{g} / \mathrm{ml}$, S. procalcitonin: $>100 \mathrm{ng} / \mathrm{mL}$, S. lactate: 77.70 mmol/1, LDH: 936 U/L, IL-6: $393.20 \mathrm{pg} / \mathrm{mL}$.

USG of whole abdomen showed features of acute hepatitis: mild hepatomegaly $(16.2 \mathrm{~cm}$ in mid hepatic plane), homogenously hypoechoic echotexture of liver parenchyma giving 'starry sky' appearance; features of bilateral acute nephropathy as both kidneys were mildly enlarged with decreased cortical echogenicity, cortico-medullary differentiation was accentuated. Also mild ascites was present.

Chest $\mathrm{x}$-ray $\mathrm{P} / \mathrm{A}$ view on admission had no significant findings. [Figure-5]

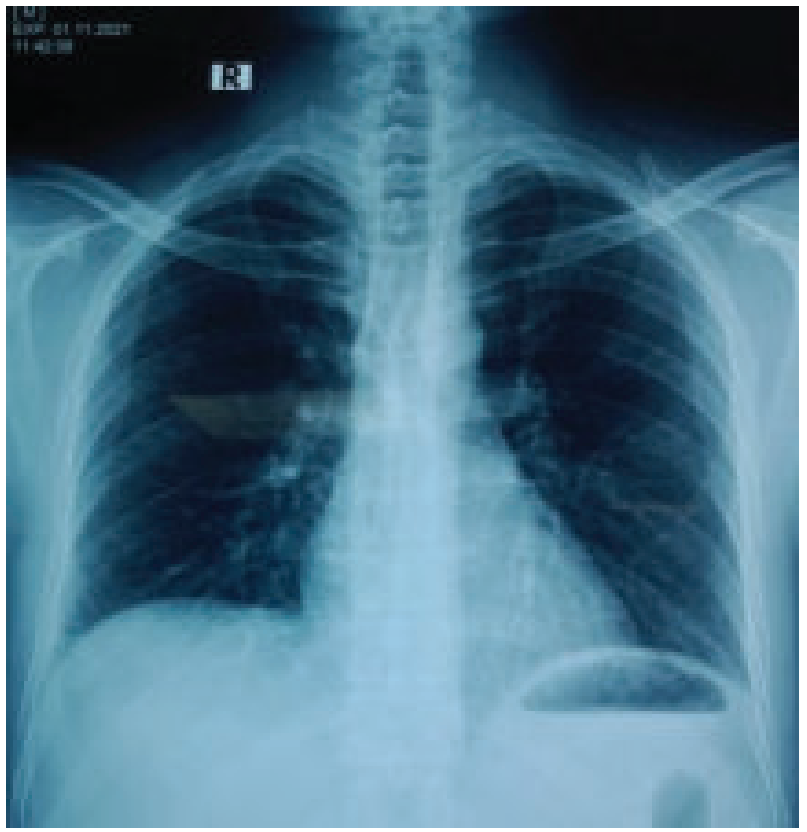

Fig.-5: Normal chest radiology on admission 


\section{His ECG tracing showed sinus tachycardia.}

Having all above documentations, we started our battle with this patient with four differentials in hand- Expanded dengue syndrome, Severe complicated malaria with MODS, Leptospirosis, and Acute viral hepatitis with hepatorenal syndrome; that needed to be excluded.

The next day, ICT for malaria (P. falciparum) came out positive and though MP on blood films came out negative. Dengue serology, Viral markers for acute hepatitis (HAV, HEV, HBV), Urinary leptospiral antigen test, and RT-PCR for COVID-19 pneumonia were negative. Despite having negative blood films for MP report, based on his clinical condition and positive ICT for malaria report, he had been diagnosed as a case of- Severe complicated malaria, and Sepsis with MODS (Acute liver failure, Acute kidney injury), Hyponatremia, Metabolic acidosis.

His treatment started immediately with Inj. Artesunate- at a dose of $2.4 \mathrm{mg} / \mathrm{kg}$ body weight according to the national revised malarial treatment regimen-2017. In the following days, his temperature peak was gradually decreasing, but patient was not fully afebrile. So, on $5^{\text {th }}$ day of Inj. Artesunate MP on blood films test was repeated once again and this time it showed P. falciparum with low parasitic count [Figure-6].

Inj. Artesunate continued up to 7 days depending on the clinical response and the lab parameters of the patient. After the completion of Inj. Artesunate, oral combination of

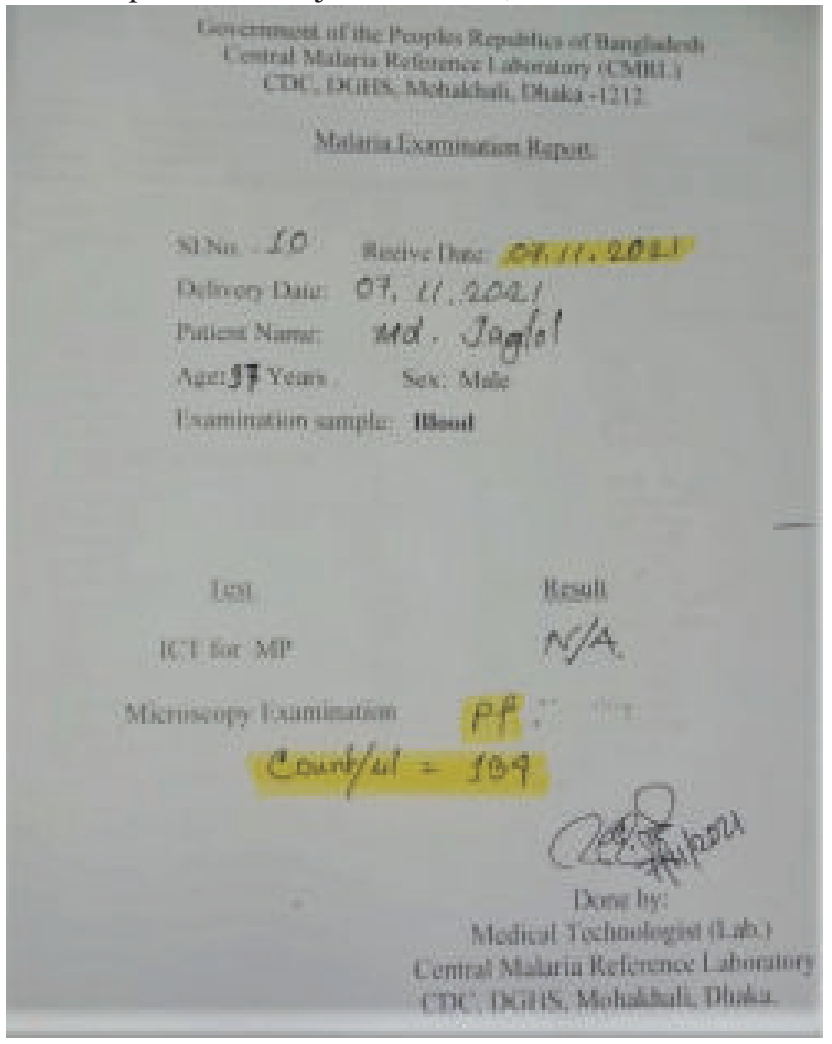

Fig.-6: MP on blood films (P. falciparum with 134/ $\mu L$ parasite count)
Artemether-Lumefantrine was given for 3 days. Patient became afebrile [Figure-7] and clinically improved. After that, his MP on blood films were repeated again to see the parasitic clearance. [Figure-8]

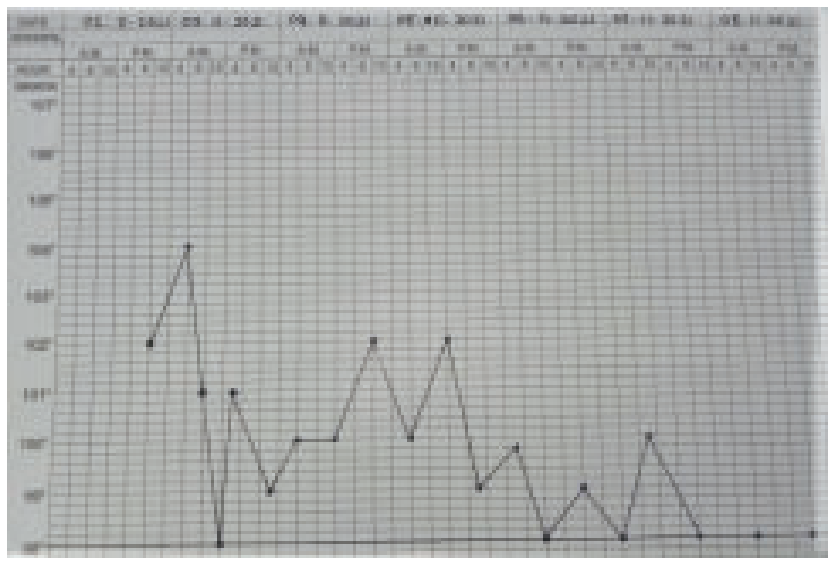

Fig.-7: Effect of anti-malarial agent on temperature

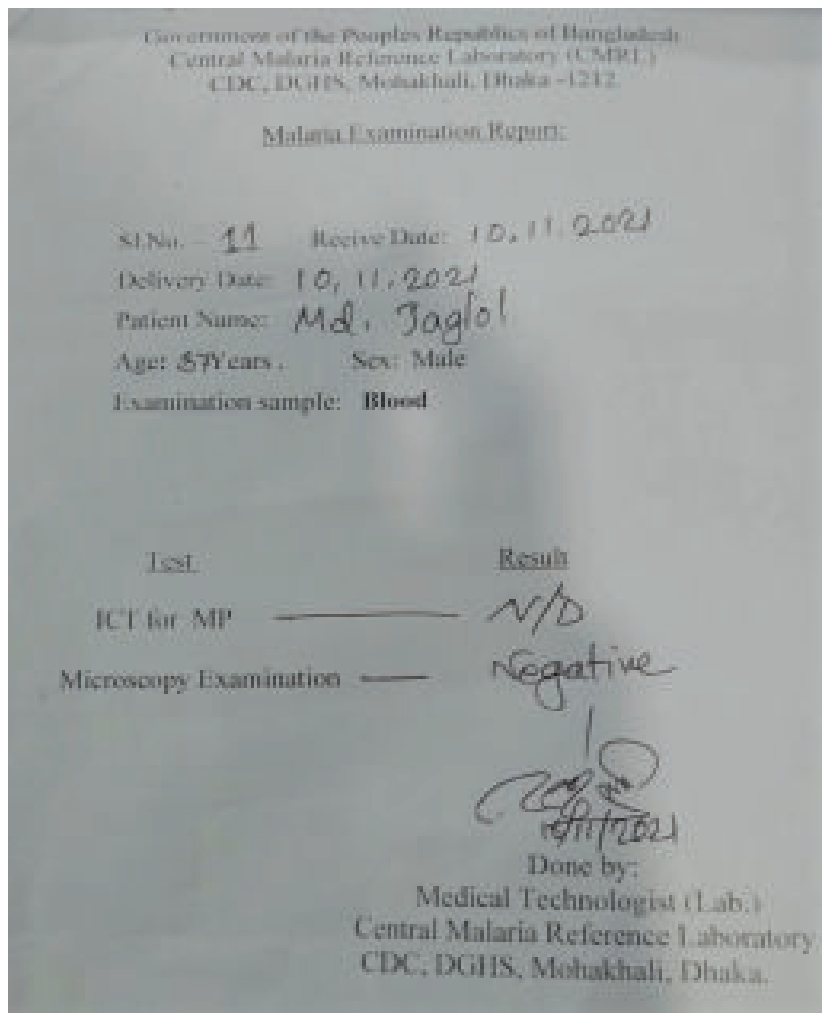

Fig.-8: MP on blood films- Negative, after completion of anti-malarial treatment.

Along with anti-malarial treatment, other necessary steps were taken accordingly for combating sepsis, AKI, metabolic acidosis, hyponatremia, hypoglycaemia and hypoalbuminemia. These complications got corrected in due time. But despite having repeated transfusions of apheretic platelet and whole blood for consecutive days, his anemia and thrombocytopenia persisted. 


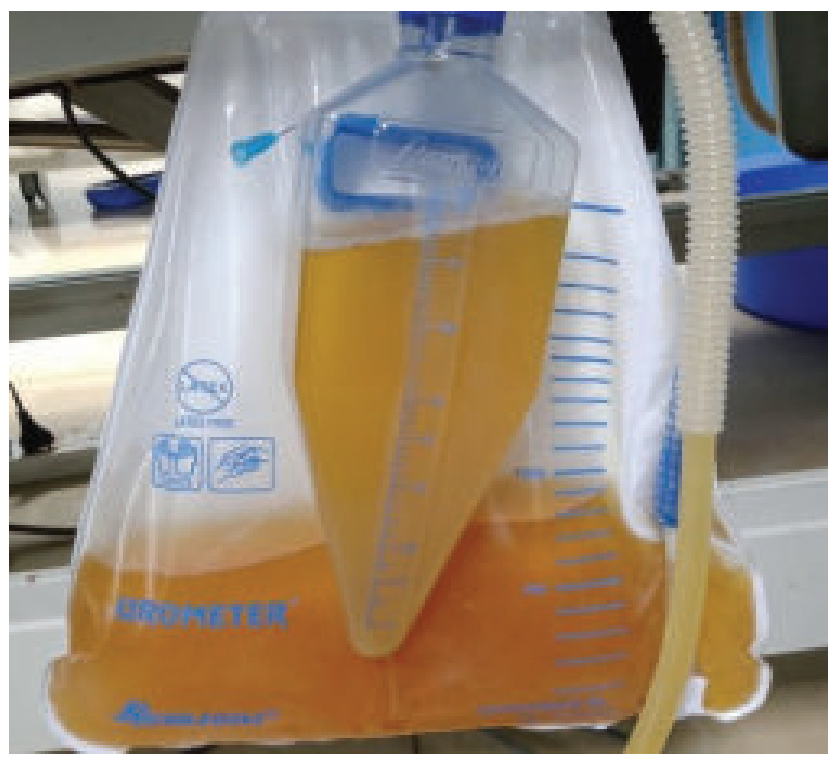

Fig.-9: Resolving phase of AKI

After being assured that, patient was clinically stable for at least 24 hours, and as his lab parameters showed improvement of LFT, RFT and inflammatory markers, he had been shifted to cabin from ICU on $11^{\text {th }}$ day of admission. But at that night in cabin, he developed high grade fever of $104^{\circ} \mathrm{F}$ with chills and rigor along with productive cough and respiratory distress. Vital parameters were- Pulse: 128bpm, BP: 120/80 mmHg, Temperature: $104^{\circ} \mathrm{F}, \mathrm{RR}: 28$ breaths/min. Auscultation of chest revealed, bronchial breath sound with coarse crepitations over right middle lung field, and diminished breath sound over right lower lung field.

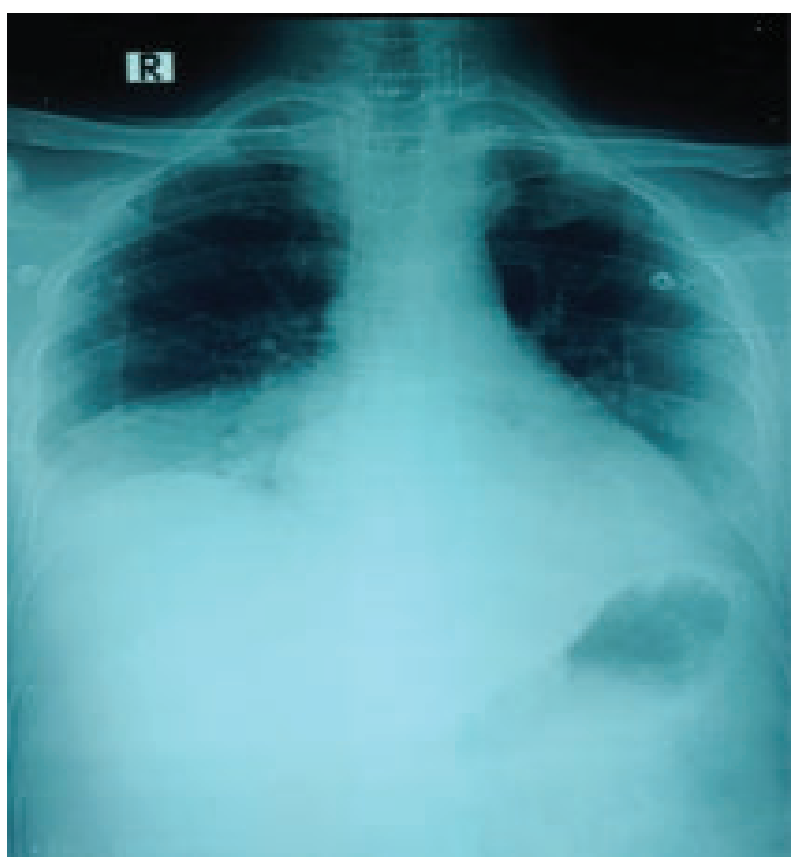

Fig.-10: Right lower lobe consolidation with parapneumonic effusion
Repeat investigations showed-CBC: Total WBC count: $15.64 \mathrm{~K} /$ $\mu \mathrm{L}$, Neutrophil: $70 \%$, Lymphocyte: $24 \%$, Hemoglobin: $8.50 \mathrm{~g} / \mathrm{dL}$, HCT: $25.10 \%$, Platelet count: $30 \mathrm{~K} / \mu \mathrm{L}$, ESR: $25 \mathrm{~mm}$ in $1^{\text {st }}$ hour.

\section{Repeat chest X-ray AP view: [Figure-10]}

Sputum C/S: Moderate growth of Klebsiella pneumoniae.

Blood C/S, Urine C/S and Tip of CV line $\mathrm{C} / \mathrm{S}$ showed no growth of any organism.

Patient had been urgently shifted to high dependency unit (HDU), but there he developed noticeable mutism, delayed responsiveness \& withdrawal of food. Nervous system examination was repeated and revealed no abnormalities, excluding the chance of cerebral malaria. Followed by, psychiatric evaluation was done, which revealed the cause as stupor due to depressive disorder.

After thorough evaluation, his diagnosis was re-defined asHospital acquired pneumonia of right lower lobe with parapneumonic effusion, Severe complicated malaria \& MODS (Resolving state), AKI (Diuretic phase), Stupor (depressive disorder).

Treatment started with Colistin in both injectable and nebulization form, and Inj. Doripenem to combat nosocomial pneumonia. For persistent thrombocytopenia, oral Eltrombopag was introduced. And for his stupor, there was an excellent response with oral Sertraline. He responded very well with these appropriate managements.

Repeat chest x-ray P/A view: After 5days of antibiotic coverage [Figure-11]

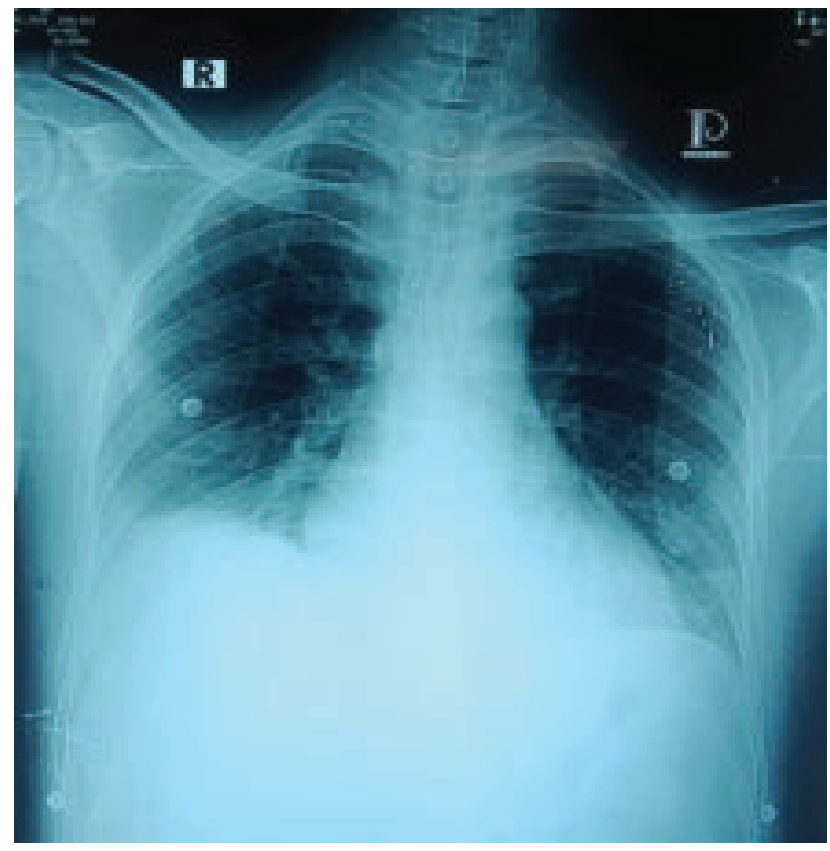

Fig.-11: Clearing shadows of consolidation and resolving parapneumonic effusion 
Comparison of different parameters from his admission to discharge are given below:

\section{Temperature chart during hospitalization:}

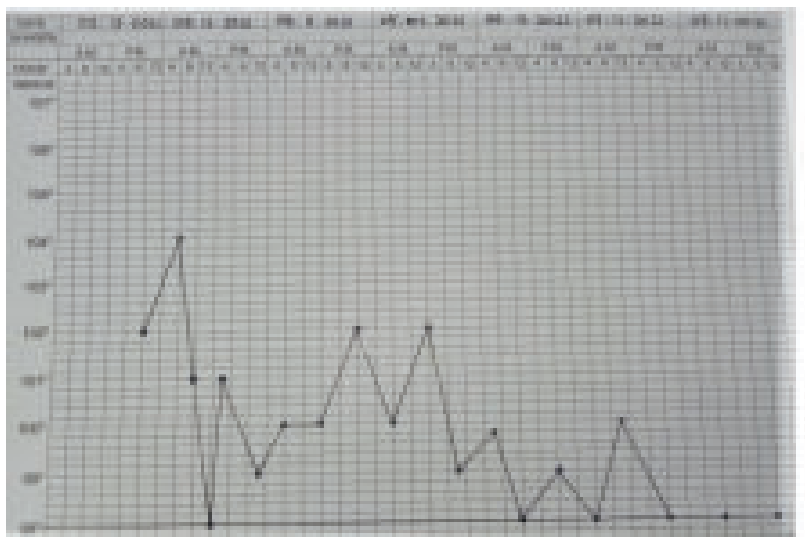

(A)

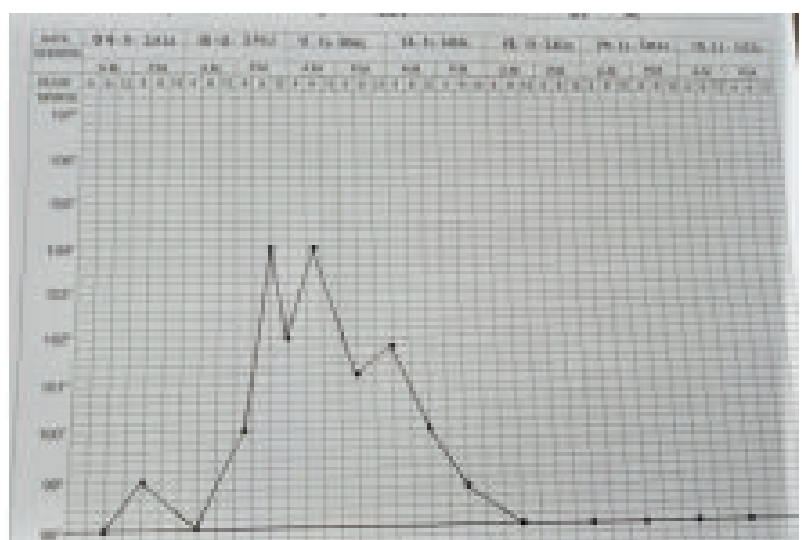

(B)

Fig.-12: (A): Effect of anti-malarial treatment. (B): Period of nosocomial pneumonia.

\section{Changes in chest radiology:}

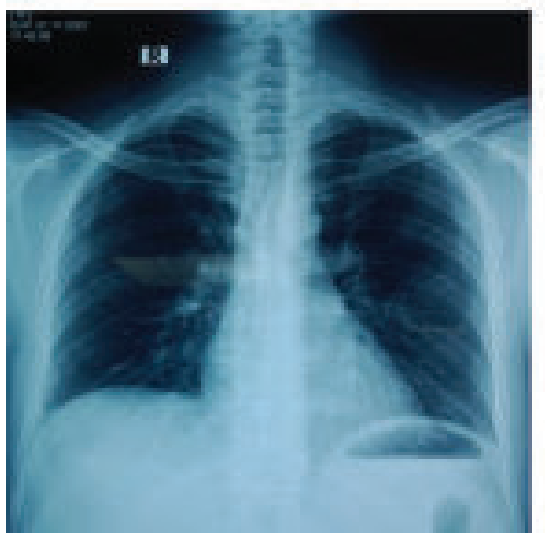

(A)

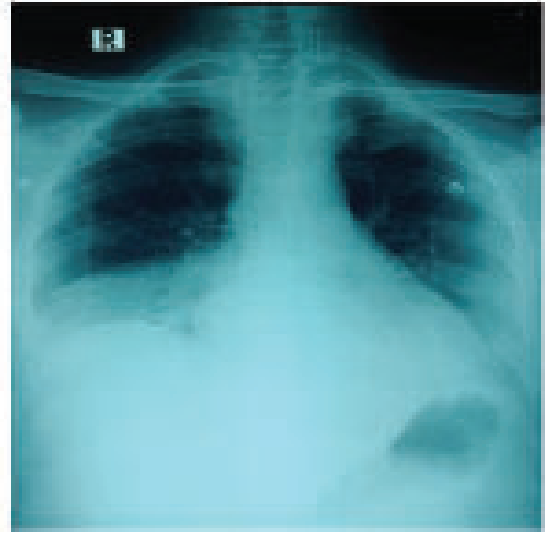

(B)

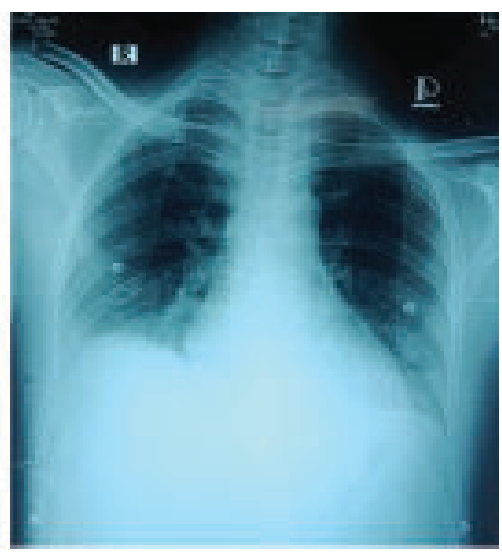

(C)

Fi.-13: (A): On admission. (B): On 11 th day of admission- Hospital acquired pneumonia. (C): On $15^{\text {th }}$ day of admissionTreatment responsiveness on hospital acquired pneumonia.

Renal improvement evident by urine colour:

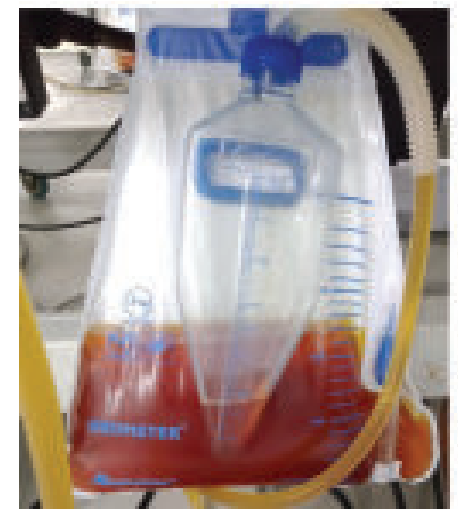

(A)

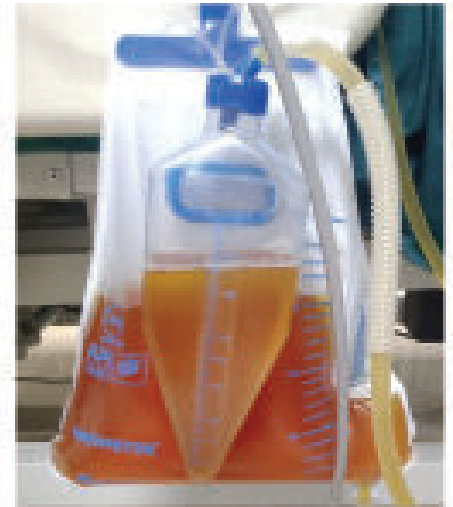

(B)

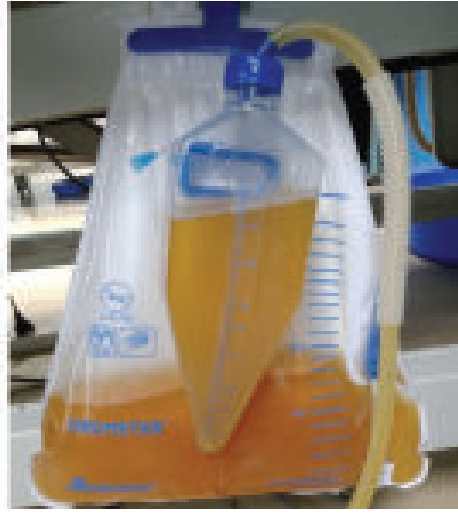

(C)

Fig.-14: (A): On admission- high coloured urine due to hyperbilirubinuria. (B): On $11^{\text {th }}$ day of admission. (C): On $15^{\text {th }}$ day of admission- near-normal urine colour. 
We were able to discharge the patient on his $16^{\text {th }}$ day of admission with stable health, and no issues [Figure-15].

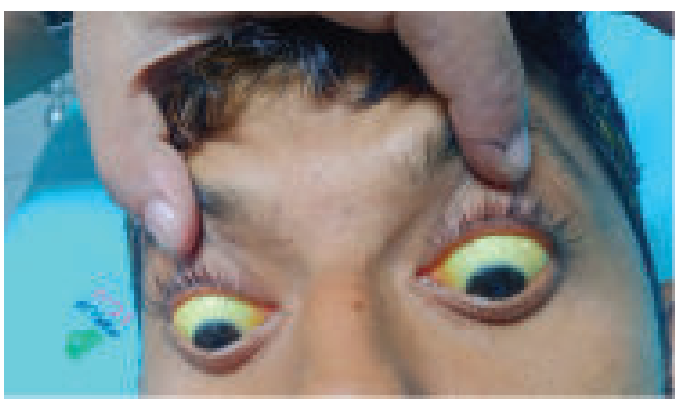

(A)

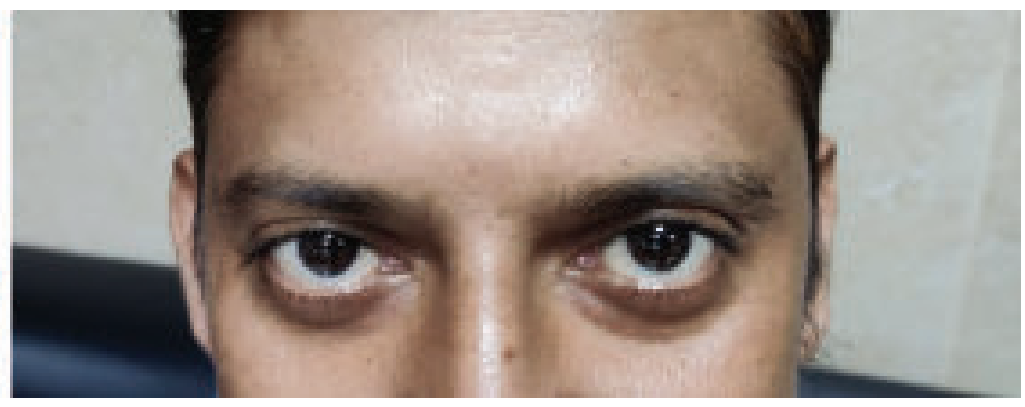

(B)

Fig.-15: (A): Moderate jaundice on admission, (B): Non-icteric with overall improved health status on discharge

Later, he was in close follow up for persistent anemia and thrombocytopenia, which finally got corrected after 1 months while other causes of this had been excluded. Follow up investigations showed: CBC- Hemoglobin: $11.90 \mathrm{~g} / \mathrm{dL}$, Platelet count: $235 \mathrm{~K} / \mu \mathrm{L}$, Total WBC count: $6.02 \mathrm{~K} / \mu \mathrm{L}$, ESR: $36 \mathrm{~mm}$ in $1^{\text {st }}$ hour. RFT and LFT came back within normal range.

\section{Discussion}

Malaria, transmitted in humans by the bite of infected Anopheles mosquito and mostly caused by five plasmodium species: P. falciparum, P. malariae, P. ovale, P. vivax, and P. knowlesi. Among the infected individuals, P. falciparum is the most common species identified (approximately $75 \%$ ), followed by P. vivax (approximately 20\%). It is common in tropical and subtropical countries. Each year nearly 290 million people are infected with malaria, and more than 400,000 people die of the disease worldwide.

People infected with malaria usually feel very sick with a high fever and shaking chills. It can have both uncomplicated and complicated disease course. Children are more prone to develop anemia and convulsions as manifestations of severe malaria, while adults face acute renal failure and jaundice more commonly. Pregnant women are vulnerable to hypoglycaemia, anemia and pulmonary complications.

Hemolysis can cause mild jaundice, whereas, hepatic dysfunction is responsible for moderate to severe jaundice. Unconjugated hyperbilirubinemia and high levels of hepatic transaminases is the usual finding. Although, hepatic encephalopathy due to hepatocellular failure is rare.

Acute kidney injury is a more common complication of malaria in adults than in children. Malarial AKI is catabolic in type, and diagnosed by rapid rise of serum creatinine and urea levels. AKI when present alone is less severe than when associated with other complications (cerebral malaria, jaundice, pulmonary edema/ ARDS).
Pulmonary edema has a high mortality rate ensuing it as a grave complication of severe malaria. Negative fluid balance, presence of AKI, severe anemia and pregnancy predispose to Adult Respiratory Distress Syndrome (ARDS) ${ }^{3}$.

Other complications of severe malaria include: Metabolic acidosis- resulting from loss of bicarbonate, increased generation of lactic acid, tissue hypoxia, increased body metabolism and failure of the hepatic clearance; Hypovolemia; Hyponatremia attributed to SIADH or excessive losses of sodium in sweat, vomitus and diarrhoea.

Blackwater fever is a clinical entity of severe malaria characterized by acute intravascular hemolysis. Classically occur as a complication of re-introduction and repeated use of quinine in long-term residents in Plasmodium falciparum endemic areas. Since 1950, when quinine was replaced by chloroquine, blackwater fever became a rare finding. Thereafter, several cases have been noted with the use of halofantrine and mefloquine, two new molecules similar to quinine (amino-alcohol family). The possible physiopathogenesis of the disease could be the concomitance of a double sensitization of the red blood cells to the $P$. falciparum red blood cells and to the amino-alcohols is necessary to provoke the haemolysis ${ }^{4}$.

Apart from its classical presentation, malaria may present with refractory anemia or pancytopenia. A descriptive study included 200 consecutive cases of fever and refractory anemia or pancytopenia from 2011 to 2014, concluded as Plasmodium falciparum should be considered in all cases of prolonged fever with refractory anemia or pancytopenia, even with negative smear and rapid antigen tests, in malaria endemic areas $^{5}$.

The case-fatality rate due to severe malaria is $10-15 \%$ in spite of therapy but it increases in the presence of renal failure or respiratory distress (pulmonary edema or ARDS). 
Early diagnosis and prompt treatment reduces the mortality due to malaria. Artemisinin compounds (viz. atremether, artesunate and arteether) are highly effective and rapid scizonticidal drugs. A multi-centric study has demonstrated the efficacy of intravenous artesunatein reducing the mortality by $30 \%$. In contrast, intravenous quinine infusion is difficult to institute, and needs constant monitoring for arrhythmia, hypoglycaemia, and severe hypotension. Treatment failures cases with Artemether-Lumefantrine have also been reported in travellers of Africa. Lumefantrine is highly lipophilic and bioavailability depends on concurrent food intake, so this can also occur due to sub-optimal Lumefantrine concentrations ${ }^{6}$.

As malaria is a preventable and curable disease, since 2007, Bangladesh's National Malaria Control Programme and its community-based activities have been implemented in partnership with the world's largest NGO- Bangladesh Rural Advancement Committee (BRAC), supervised by the Directorate General of Health Services. The programme invests in both preventive and curative malaria measures. As a result, malaria prevalence decreased by $65 \%$ from 2007 to 2012 , and by $81 \%$ from 2010 to $2018^{7}$.

\section{Targets and achievement of NMEP:}

\begin{tabular}{lccc}
\hline & 2008 & 2020 & $\begin{array}{c}\text { Fall in } \\
\text { cases }\end{array}$ \\
\hline Incidence of malaria cases & 84.690 & 6130 & $93 \%$ \\
Number of severe malaria cases & 3042 & 92 & $97 \%$ \\
Total malaria deaths & 154 & 9 & $94 \%$ \\
\hline
\end{tabular}

\section{Malaria incidence (per 1000 population at risk), 2000 to 2018}

Incidence of malaria is the number of new cases of malaria in a year per $100 \begin{gathered}\text { Dur Worta } \\ \text { in data }\end{gathered}$ populatio ar tisk. SDG target 3.3 is to end the epidemic of malaria
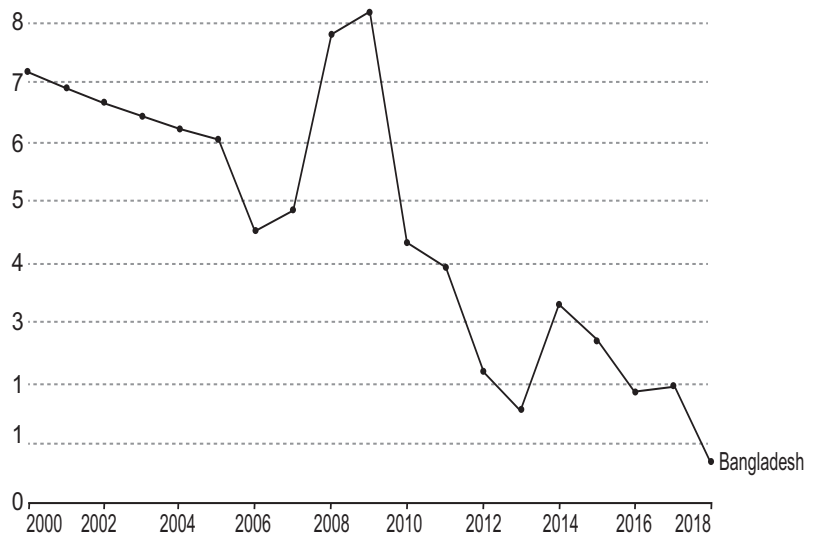

Source : World Health Organization (via World Bank)

Fig.-16: Fall in malaria incidence in Bangladesh from 2000 to 2018 (Source: WHO)
Bangladesh implemented its 'National Strategic Plan 20172021 ' to ensure it is free of malaria by the year 2030, led by the National Malaria Elimination Program (NMEP) and in partnership with BRAC.

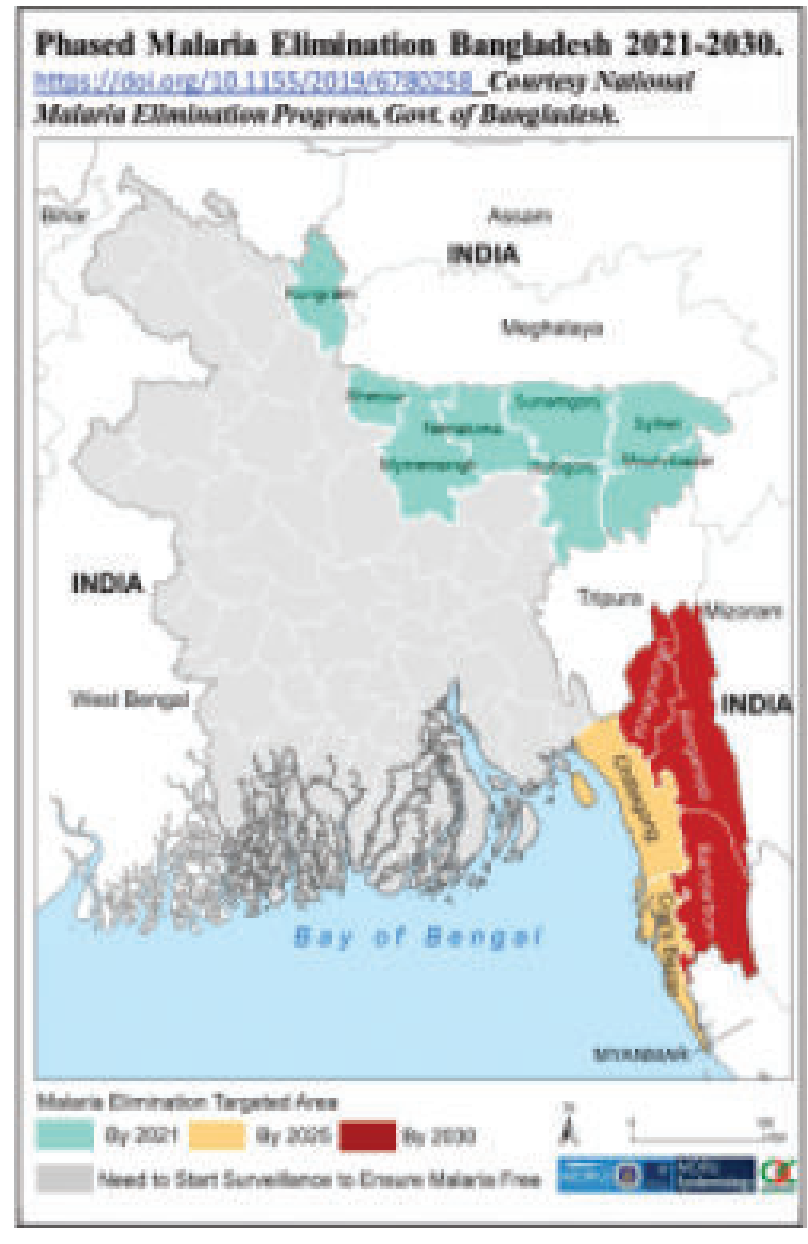

Fig.-17: Targeted area of phased malaria elimination Bangladesh 2021-2030. [Green area: by 2021, Yellow area: by 2025, Red area: by 2030]

However, since 2019 there is a notifiable increase in malaria case in Bangladesh. Among the new cases, over $90 \%$ occur in the Chittagong Hill Tracts (CHT) districts (Khagrachhari, Rangamati and Bandarban) where hundreds of thousands of refugees have fled to from Myanmar due to FDMNs, increasing the threat of spread of drug resistant parasites. Also, transmission of malaria is directly affected by changes in rainfall, temperature and humidity, as it is a vector-borne disease. Bandarban showed marked increase in rainfall late in 2019, as well as some increase late 2018. In addition, global pandemic of COVID-19 pneumonia has markedly halted the anti-malarial campaign. All these factors together now attributing to the resurgence of malaria in the country. 
Malaria status of Bangladesh from January'21 to October'21 (Source: CDC, DGHS):

\begin{tabular}{lcccc}
\hline $\begin{array}{l}\text { Total test +ve } \\
(\text { Blood slide +RDT) }\end{array}$ & $\begin{array}{c}\text { Uncomplicated } \\
\text { Malaria (UM) }\end{array}$ & $\begin{array}{c}\text { Severe malaria } \\
(\mathrm{SM})\end{array}$ & $\begin{array}{c}\text { Vivax malaria } \\
(\mathrm{VM})\end{array}$ & $\begin{array}{c}\text { Total no. of } \\
\text { Deaths }\end{array}$ \\
\hline 6381 & 4495 & 145 & 1741 & 8 \\
& & & & (All of them are SM) \\
\hline
\end{tabular}

This must be the high time to take proper measures to fight this endemic while we are living in the era of another pandemic.

\section{Abbreviations:}

BPM: Beats per minute, RBS: Random blood sugar,

LFT: Liver function test, RFT: Renal function test

NMEP: National malaria elimination program, WHO: World health organization

CDC: Centre for disease control, DGHS: Directorate General of Health Services

\section{References:}

1. Paul BK. Malaria in Bangladesh. Geographical Review. 1984 Jan 1:63-75.

2. Islam N, Bonovas S, Nikolopoulos GK. An epidemiological overview of malaria in Bangladesh. Travel medicine and infectious disease. 2013 Jan 1;11(1):29-36.

3. Mishra SK, Mohanty S, Mohanty A, Das BS. Management of severe and complicated malaria. Journal of postgraduate medicine. 2006 Oct 1;52(4):281. (3)
4. Bruneel F, Gachot B, Wolff M, Bedos JP, Regnier B, Danis M, Vachon F. Blackwater fever. Presse medicale (Paris, France: 1983). 2002 Sep 1;31(28):1329-34.

5. Hayat Z, Ullah I, Hayat K, Khan HA, Raziq F, Khan H. Refractory anemia and pancytopenia as presentations of falciparum malaria in population of khyber pakhtunkhwa, pakistan. Gomal Journal of Medical Sciences. 2019 Sep 30;17(3):75-80.

6. Färnert A, Ursing J, Tolfvenstam T, Rono J, Karlsson L, Sparrelid E, Lindegårdh N. Artemether-lumefantrine treatment failure despite adequate lumefantrine day 7 concentration in a traveller with Plasmodium falciparum malaria after returning from Tanzania. Malaria journal. 2012 Dec;11(1):1-4.

7. Matin MA, Sarkar ND, Phru CS, Ley B, Thriemer K, Price RN, Peeters Grietens K, Ali Khan W, Alam MS, Gryseels C. Precarity at the margins of malaria control in the Chittagong Hill Tracts in Bangladesh: a mixed-methods study. Pathogens. 2020 Oct;9(10):840. 